\title{
Challenges in Atrial Septal Defect Occlusion
}

\author{
Roie Tal, MD¹, Moshe Dotan, MD², Yitzhack Schwartz, MD¹, Avraham Lorber, MD ${ }^{*}$ \\ ${ }^{1}$ Pediatric Cardiology and Adults with Congenital Heart Disease Institute, Rappaport Children's Hospital, Rambam Health Care \\ Campus, Haifa, Israel \\ ${ }^{2}$ Pediatric Cardiology, Ziv Medical Center, Safed, Israel
}

\begin{abstract}
We present 11 cases of percutaneous transcatheter occlusion of atrial septal defects (ASDs) in adults, including multi-fenestrated ASD, balloon-assisted deployment of ASD occlude, dilator-assisted deployment of ASD occlude, "cobra"-shaped disfiguration of the left disc, ASD with deficient aortic rim, pulmonary vein-assisted deployment of ASD occlude, "high" ASD, large Chiari network, double interatrial septum, snaring a runaway occluder, and right ventricular diastolic dysfunction causing cyanosis. Each case is followed by a practical discussion of the special dilemmas, complications, and challenges that may occur during common procedures.

Copyright $\odot 2017$ Science International Corp.
\end{abstract}

\section{Key Words}

Atrial septal defect - Percutaneous occlusion • Challenge • Technique

\section{Introduction}

Atrial septal defects (ASDs) account for 10-17\% of congenital cardiac anomalies. Percutaneous closure of ostium secundum ASD is a safe and effective alternative to surgery [1]. Nevertheless, as with any interventional procedure, some ASD closures pose challenges and dilemmas to the interventional cardiologist. We report a variety of 11 representative cases, highlighting challenging morphological and clinical considerations that are of educational and practical value and suggesting ways to avoid pitfalls and com-

C 2017 Journal of Structural Heart Disease Published by Science International Corp. ISSN 2326-4004 plications. These observations were collected over an 18-year period during which we have implanted over 1,000 interatrial shunts using the percutaneous approach.

\section{Multi-Fenestrated ASD}

A 45-year-old patient was evaluated after a cerebrovascular attack. Transthoracic echocardiography (TTE) revealed a floppy interatrial septum (IAS) with four fenestrations (Figure 1). A spontaneous left-toright flow was noted as well as free right-to-left micro-bubble flow during the Valsalva maneuver. We decided to close the fenestrations with a single device. A first attempt with a $15-\mathrm{mm}$ device deployed in

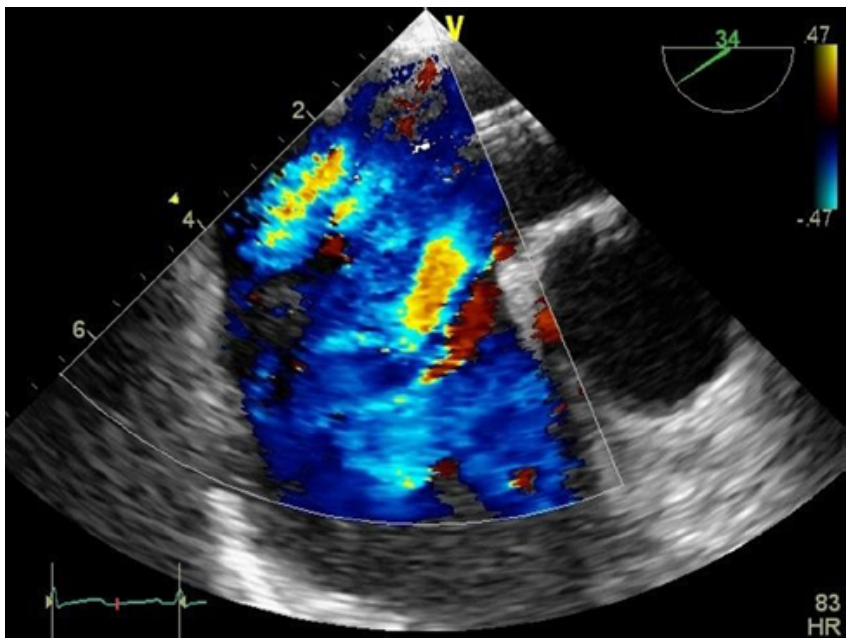

Figure 1. Transesophageal echocardiogram demonstrating a multifenestrated atrial septal defect with four openings.

* Corresponding Author:

Avraham Lorber

Pediatric Cardiology and Adults with Congenital Heart Disease Institute

Rappaport Children's Hospital, Rambam Health Care Campus

HaAliya HaShniya St 8, Haifa, 3109601, Israel

Tel. +1 9724 7774630, Fax: +1 9724 7774690, E-Mail: a_lorber@rambam.health.gov.il 


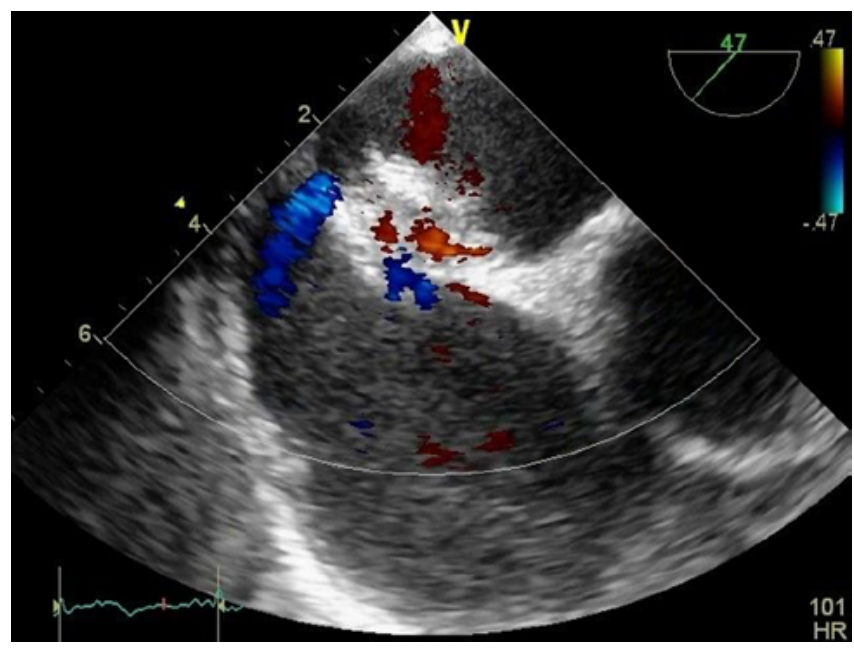

Figure 2. Transesophageal echocardiogram demonstrating a deployed occluding device in one of the atrial septal defects. A leak is present outside the perimeter of the device.

one of the central defects failed to occlude all openings (Figure 2). A second attempt was performed in the adjacent central defect using a 21-mm occluder. Residual leak was demonstrated only within the perimeter of the device (Figure 3). At this stage, the device was released.

The transcatheter closure of a multiple or fenestrated ASD can be accomplished by several methods [2]. The defects can be closed by the use of several devices, with each implanted to close one or more defect. When the distance between the ASDs is greater than $7 \mathrm{~mm}$, placement of two devices is recommended [3]. Closure of the larger defect should be performed first $[3,4]$. The second device may then need to be larger to overlap the rim of the first device, despite the smaller stretched diameter of the defect. When using more than one device, attention should be paid to maintaining adequate distance from structures like vena cavae entrances and the coronary sinus. The devices might interfere with blood flow and even increase the risk of thrombosis. This, however, has not been apparent in follow-up studies, even after cessation of antiplatelet therapy [5]. In addition, the devices might cause erosion of important tissues, including the aortic root, atrioventricular valves, or atrial free walls. Nevertheless, closure of multiple ASDs using multiple occluders seems to be a safe and effective method. Also, a financial issue that should be considered when implanting more than one device is the re-

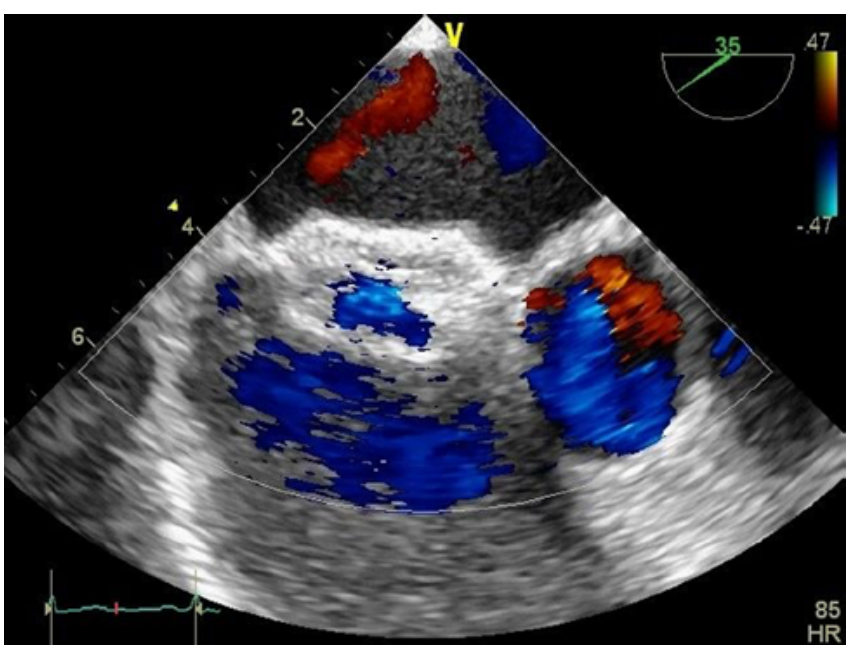

Figure 3. Transesophageal echocardiogram demonstrating a deployed occluding device in one of the atrial septal defects. Residual shunt is present within the perimeter of the device.

imbursement system used by current health maintenance organizations [2]. As the cost of percutaneous closure of ASD is reimbursed according to a specific diagnosis-related group, closing multiple ASDs with more than one device during a single procedure will exceed the diagnosis-related group budget.

When the defects are in close proximity, an attempt may be made to close all defects using a single device. Szkutnik et al. [6] reported the feasibility of this approach in 2004. A distance of less than $7 \mathrm{~mm}$ between defects is considered appropriate for this procedure, and a larger device should be employed to cover all the defects. In addition to the diameter of the device, a decision must be made regarding the type of device. A single regular ASD occluder inserted through the central or largest defect will be stabilized in place by its waist, which will also stretch the IAS, thereby bringing the surrounding defects in proximity and decreasing their size. The benefits of using a single device are a shorter procedure duration and less chance of interference with venous blood flow, atrioventricular valve function, or adjacent tissue erosion.

\section{Balloon-Assisted Deployment of ASD Occluder}

A 38-year-old female with a history of systemic lupus erythematosus was admitted for closure of a $15-\mathrm{mm}$ secundum ASD associated with aneurysmat- 


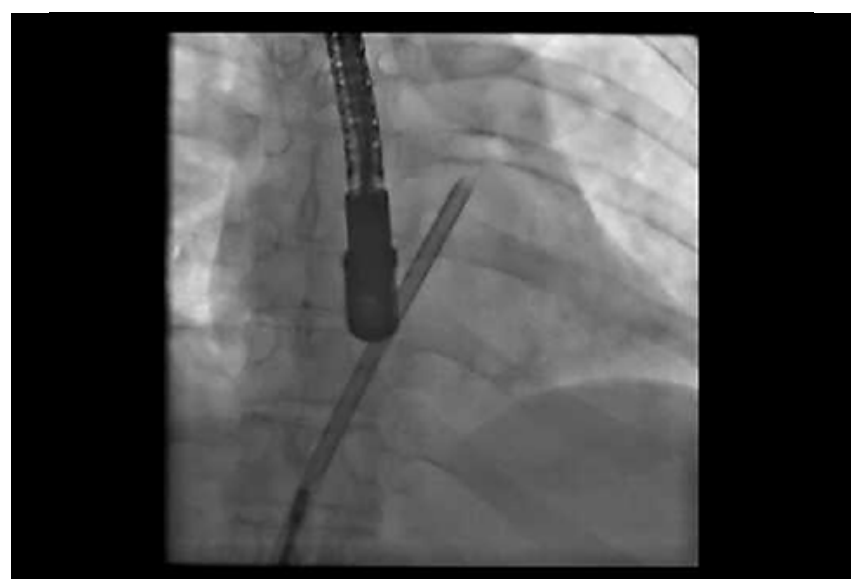

Video 1. The occluder was malaligned with the defect. View supplemental video at http://dx.doi.org/10.12945/j.jshd.2016.005.16. vid.01.

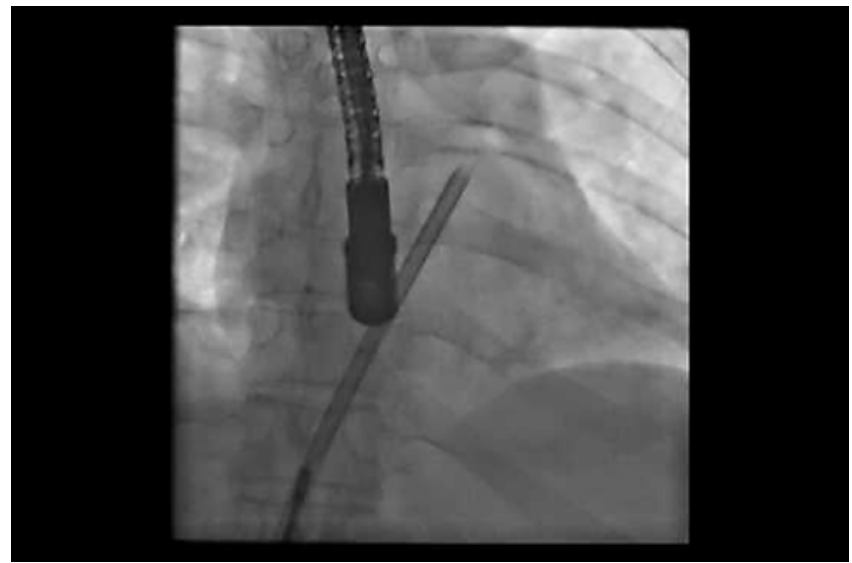

Video 2. The balloon was partially inflated in the defect. View supplemental video at http://dx.doi.org/10.12945/j. jshd.2016.005.16.vid.02.

ic IAS. In the catheterization laboratory, the occluder failed to align properly with the defect, causing the left disc to be easily pulled through the ASD in repeated attempts of deployment (Video 1), including clockwise rotation of the sheath to allow initial deployment of the left atrial disc in the vicinity of the right upper pulmonary vein. To stabilize the device, a balloon was inserted through an additional femoral venous sheath and partially inflated in the left atrium (LA; Video 2). The left disc was then deployed and held in the LA by the balloon. While the left disc was anchored in the LA, the right disc was pulled and uncovered in the right atrium (RA) and then advanced toward the IAS, engaging it appropriately (Video 3).

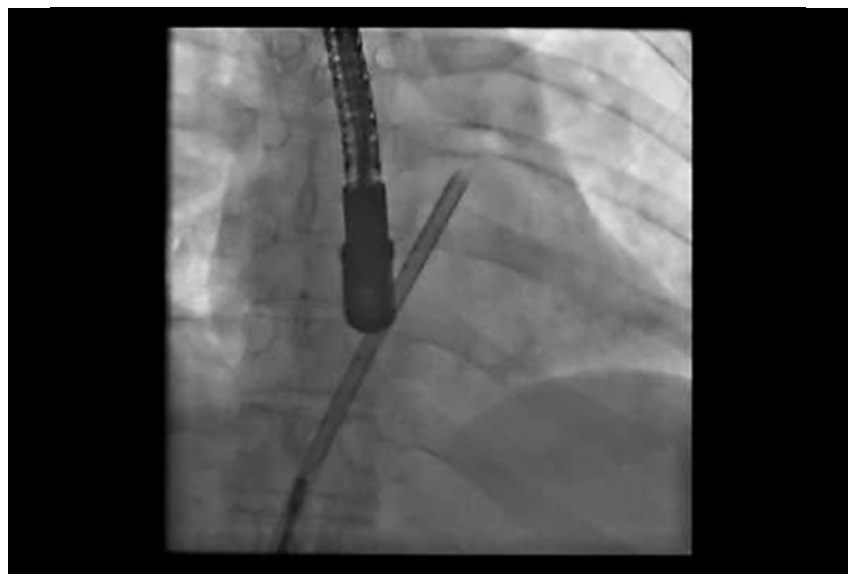

Video 3. The left disc is deployed and held in the left atrium by the balloon. The right disc was uncovered in the right atrium, engaging the interatrial septum. View supplemental video at http://dx.doi.org/10.12945/j.jshd.2016.005.16.vid.03.

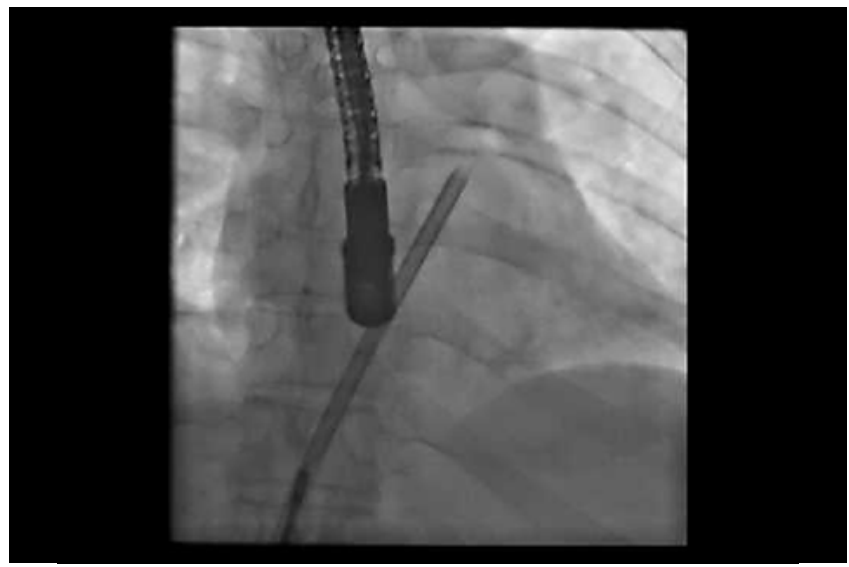

Video 4. Balloon deflation and retrieval while the left disc engaged the left aspect of the interatrial septum. View supplemental video at http://dx.doi.org/10.12945/j.jshd.2016.005.16.vid.04.

The balloon was deflated and carefully retrieved, allowing the left disc to approach the septum (Video 4). The guidewire was also slowly pulled back. The device remained in a suitable position following its release (Video 5).

The balloon-assisted technique can assist in the proper positioning of devices in difficult ASDs [7, 8]. In one case series, balloon-assisted device closure of large ( $\geq 35 \mathrm{~mm}$ ) ASDs had a $90 \%$ success rate [9]. The balloon-assisted technique facilitates controlled delivery and device alignment in very large ASDs and is often helpful when conventional delivery fails. 


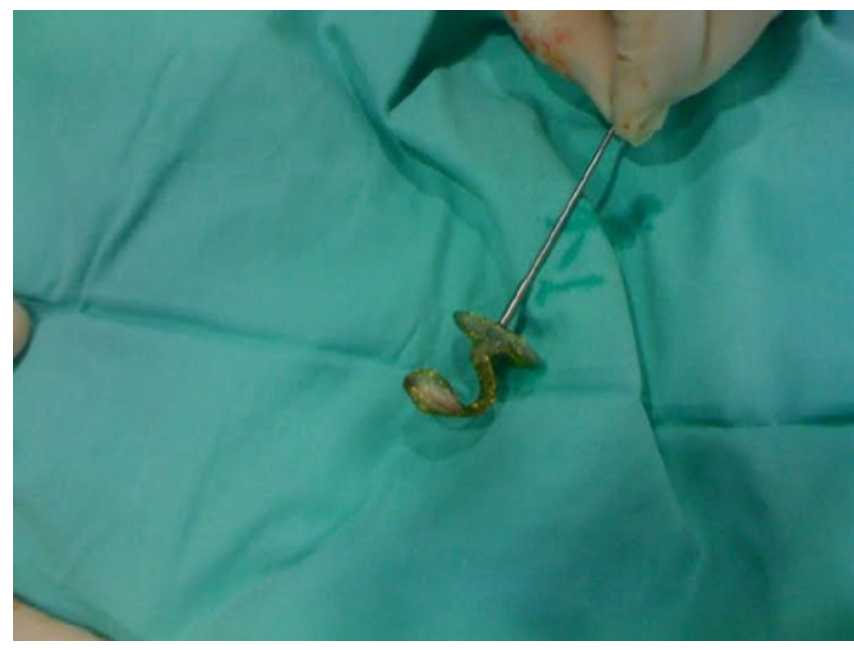

Figure 4. Extracted device.

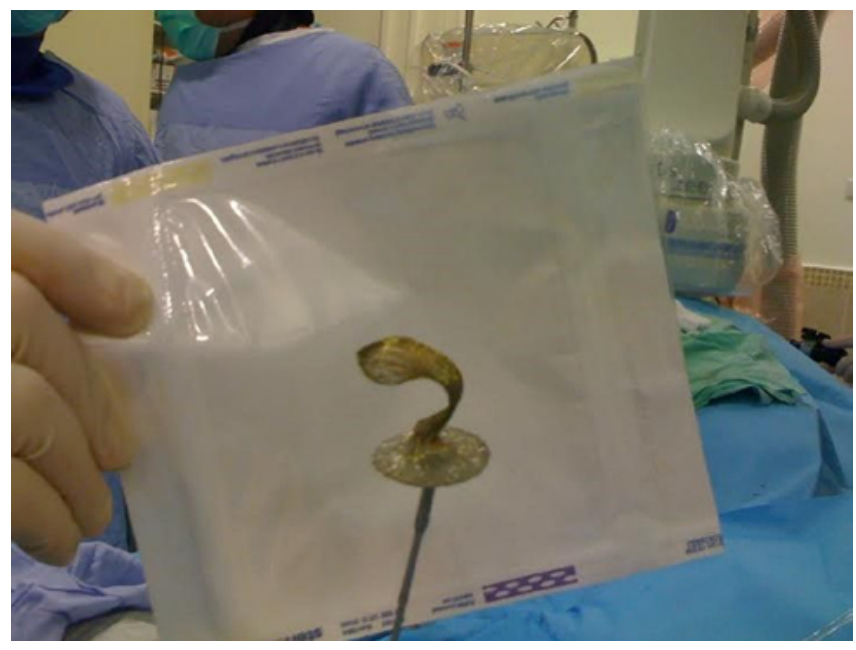

Figure 5. Extracted device.

\section{Dilator-Assisted Deployment of ASD Occluder}

A 62-year-old female was admitted for closure of a large secundum ASD causing exertional dyspnea. A 32-mm ASD with reasonable margins was measured by TEE (Video 6). The occluding device did not align appropriately with the IAS during multiple attempts (Videos 7 and 8). Therefore, the long dilator of the device delivery system was introduced over a J-wire through an additional venipuncture (Video 9). The dilator was used to retain the left disc in the LA as the right disc was uncovered and pulled gently toward the RA, allowing engagement of the IAS from the right aspect (Videos 10 and 11). This technique has also been shown to aid the closure of large ASDs

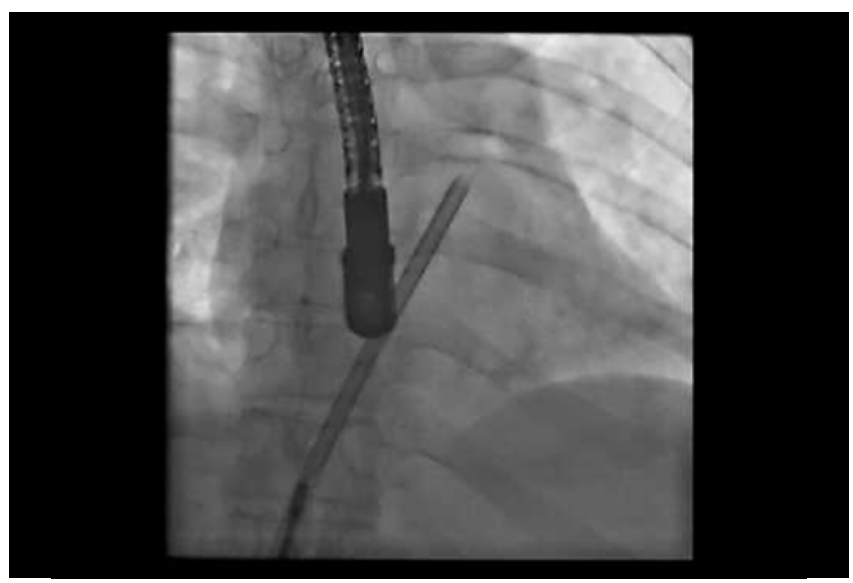

Video 5. The occluder was released and remained in position. View supplemental video at http://dx.doi.org/10.12945/j. jshd.2016.005.16.vid.05.

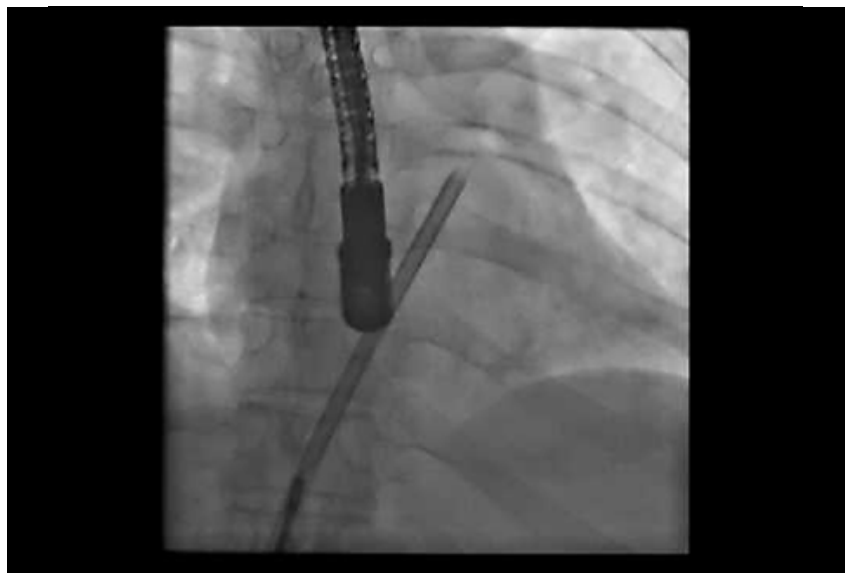

Video 6. A 32-mm atrial septal defect with reasonable margins. View supplemental video at http://dx.doi.org/10.12945/j. jshd.2016.005.16.vid.06.

when difficulties in proper deployment of the occlusive device are encountered $[10,11]$.

\section{"Cobra"-Shaped Disfiguration of the Left Disc}

During advancement of the septal occluder through the sheath, twisting or compression of the occluding device prohibited the left atrial disc from acquiring its proper "mushroom" shape, resulting in a "cobra"-shaped disfiguration (Video 12). The devices could not be deployed in this configuration and had to be removed and discarded (Figures 4 and 5). Previously published techniques using the Amplatzer septal occluder to overcome this "cobra"-like formation have included retrieving the device into the sheath 


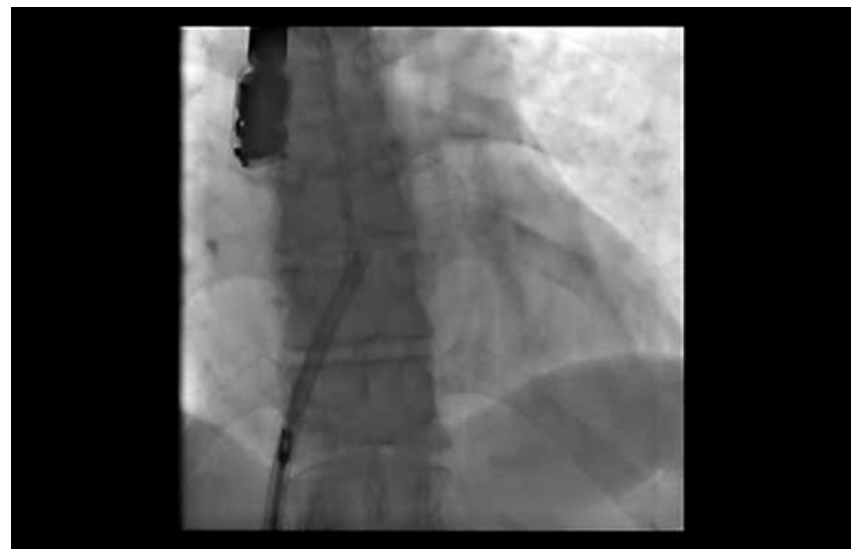

Video 7. The occluder failed to align appropriately with the interatrial septum. View supplemental video at http://dx.doi. org/10.12945/j.jshd.2016.005.16.vid.07.

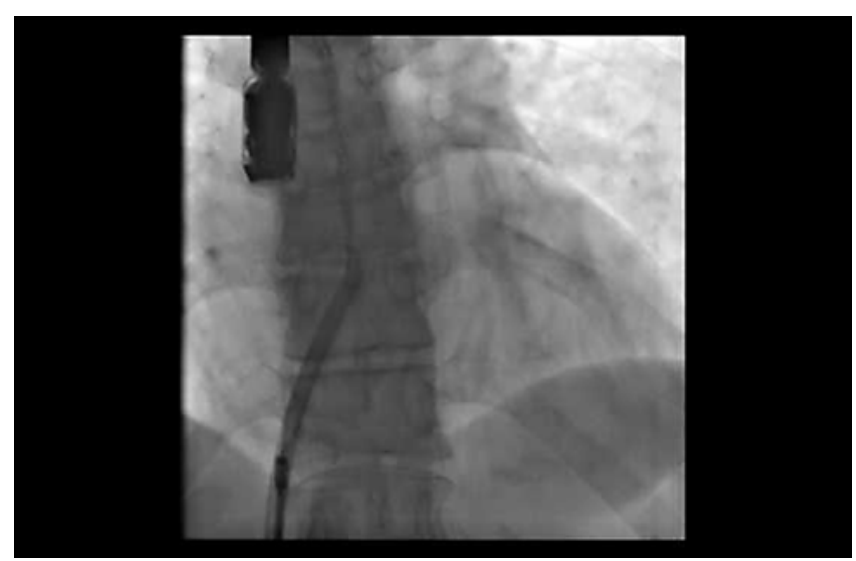

Video 8. Another failed attempt to align the occluder with the interatrial septum. View supplemental video at http://dx.doi. org/10.12945/j.jshd.2016.005.16.vid.08.

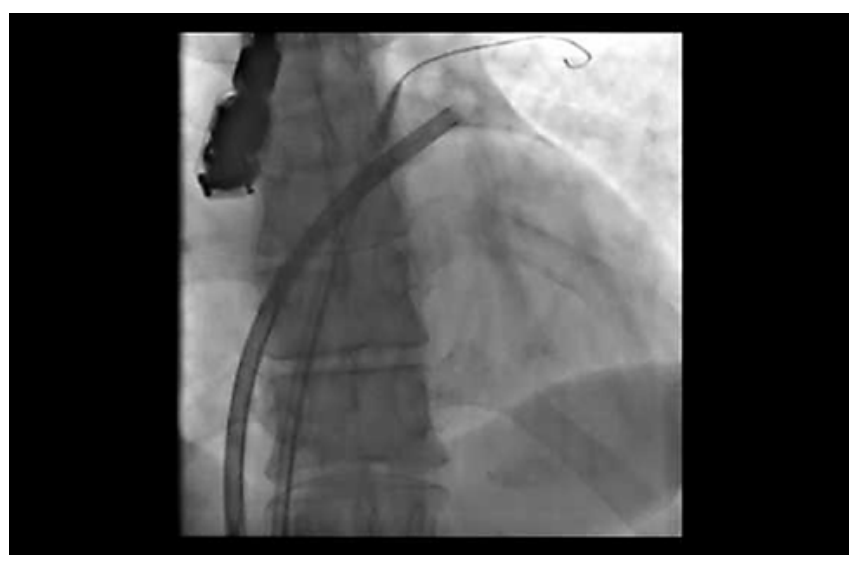

Video 9. The dilator was introduced to facilitate deployment. View supplemental video at http://dx.doi.org/10.12945/j. jshd.2016.005.16.vid.09.

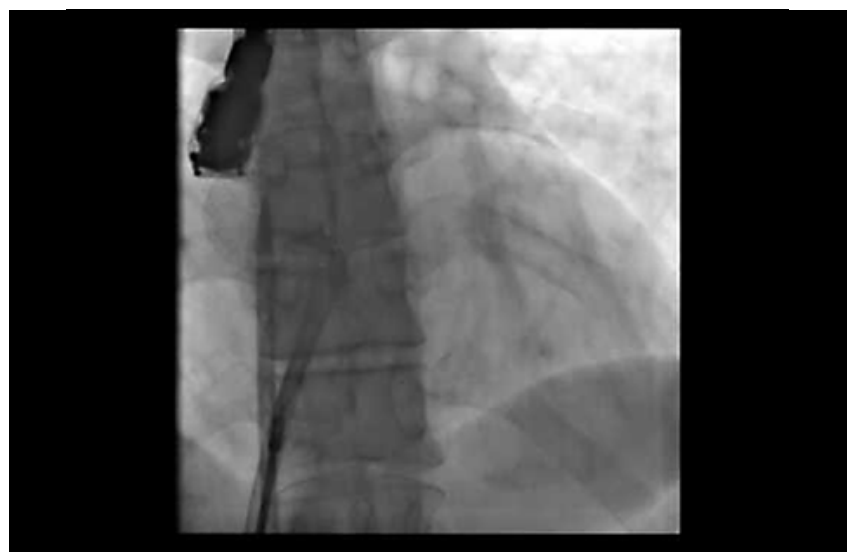

Video 10. The dilator retained the left disc in the left atrium, allowing engagement of the interatrial septum from the right. View supplemental video at http://dx.doi.org/10.12945/j. jshd.2016.005.16.vid.10.

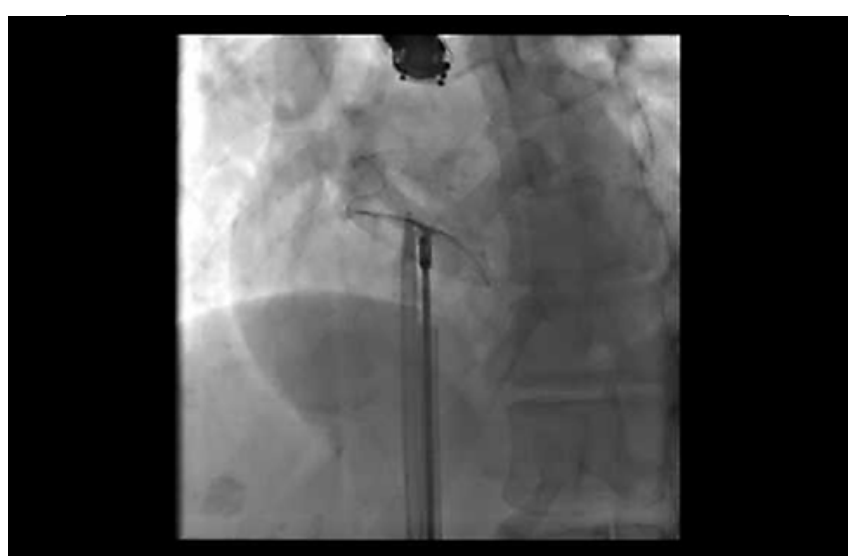

Video 11. After successful deployment the dilator is withdrawn. View supplemental video at http://dx.doi.org/10.12945/j. jshd.2016.005.16.vid.11.
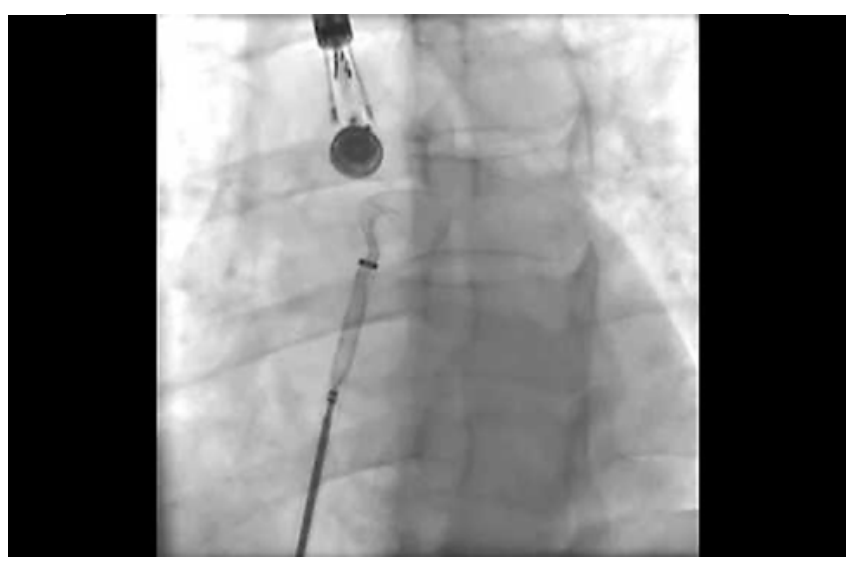

Video 12. "Cobra"-shape disfiguration of the left disc. View supplemental video at http://dx.doi.org/10.12945/j.jshd.2016.005.16. vid.12. 


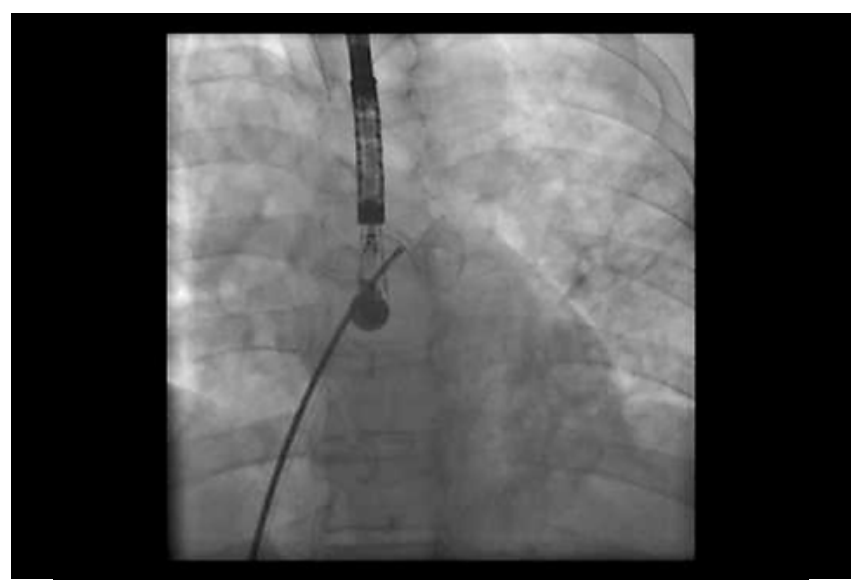

Video 13. Deploying the entire device in the left atrium allowed the device to return to its original shape. View supplemental video at http://dx.doi.org/10.12945/j.jshd.2016.005.16.vid.13.

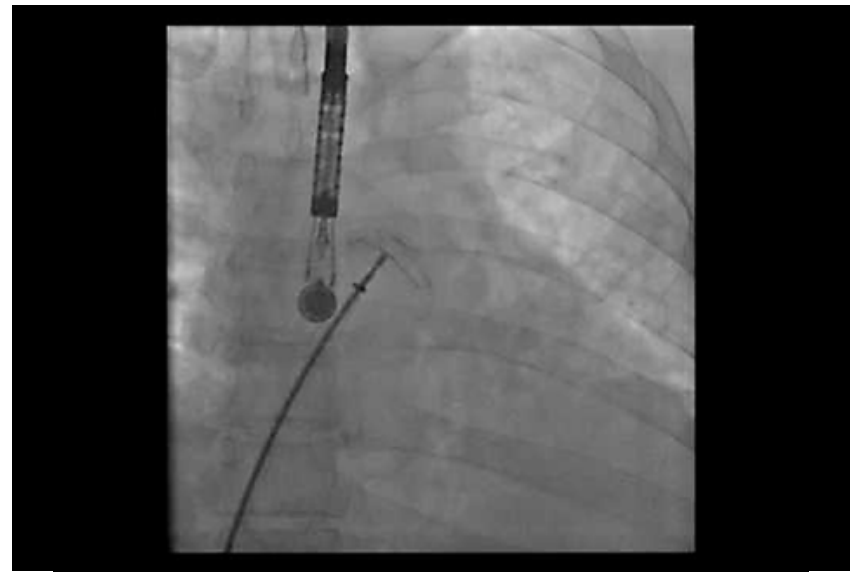

Video 14. Deploying the entire device in the left atrium allowed the device to return to its original shape. View supplemental video at http://dx.doi.org/10.12945/j.jshd.2016.005.16.vid.14.

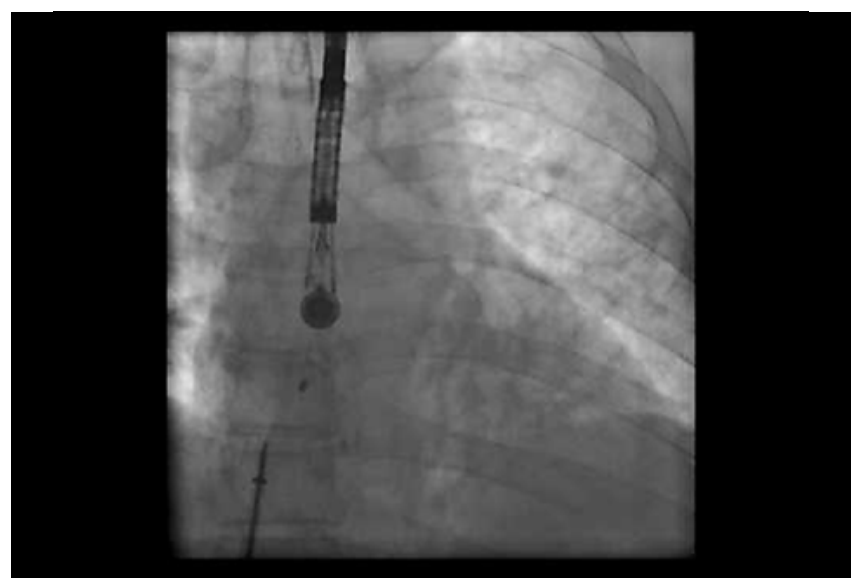

Video 15. Normal deployment and release of the device was possible. View supplemental video at http://dx.doi.org/10.12945/j. jshd.2016.005.16.vid.15. and quickly redeploying the distal disc [12], repeating the procedure several times [13], and loading the device into the sheath while making back-and forth movements in the sheath [14]. Such attempts were at least partially effective in regaining normal device configuration. In our case, using the Occlutech device, we deployed the entire device in the LA (Video 13), allowing it to assume its original shape (Video 14). It was then possible to retrieve the right atrial disc and redeploy the device in the appropriate site with a normal configuration (Video 15). This technique may be effectively applied for all devices with "cobra"-like formations [15]. With the development of new technologies, however, this obstacle is less frequently encountered.

\section{Deficient Aortic Rim}

Deficient aortic rim is a rather common morphologic feature of ASD and is present in up to $30-50 \%$ of ASDs that are considered complex [16]. Deficient aortic rim is a risk factor for aortic erosion after device closure of ASDs. Deficient aortic rim has been associated with increased risk of device impingement on the aorta, but we observed no association between device impingement and the development of aortic insufficiency (Video 16). Ostermayer et al. found that small aortic rim is independently associated with procedural failure [17]. On the other hand, O'Byrne et al. found that deficient aortic rim is highly prevalent but does not seem to increase the risk of adverse outcomes [18]. Another group found that procedural failure mainly occurs with extremely large defects $(\geq 40 \mathrm{~mm})$, regardless of whether an aortic rim of septal tissue was present [19].

Absent aortic rim is not a contraindication for transcatheter closure attempt, but it may result in a more complex procedure and require maneuvers for successful deployment of the device. It is also important to consider whether to minimize the size of the device so that its edges/discs approach the aortic root or whether to select a slightly larger device that would embrace the aortic root to minimize the risk of aortic root erosion. These cases should be thoroughly investigated by TEE to demonstrate the extent of the aortic rim deficiency from several aspects, including 3-dimensional TEE. Adverse effects following an inter- 
ventional closure of ASD in the presence of complex and extensively deficient aortic rim may occur not during the procedure but might become evident after the period of hospital stay. The complexity of the morphological anomaly should prompt questions about the safety and possible outcomes of the interventional procedure and the consideration of alternative surgical options that are safe and have a high likelihood of successful and uneventful outcomes. New technologies such as magnetic resonance imaging with 3-dimensional printing of a model representing the abnormal morphology may assist in decision-making in cases of complex anatomy.

\section{Pulmonary Vein-Assisted Deployment of ASD Occluder}

An asymptomatic 3-year-old boy was admitted for elective closure of a secundum ASD. TEE showed that the ASD measured $11 \mathrm{~mm}$ and had a deficient antero-superior aortic rim. In the catheterization laboratory, multiple attempts were made to achieve an adequate device position; however, the device slipped through the defect or resulted in a posture perpendicular to the defect (Video 17). To overcome this difficulty, we first deployed the right atrial disc and swiftly advanced it to the right aspect of the IAS, which allowed an optimal alignment of the left atrial disc with the IAS, occluding the defect. To delay the deployment of the left atrial disc, we started the deployment in the left upper pulmonary vein (LUPV). When the left disc was uncovered in the LUPV, we held it stationary in an elongated form, allowing unsheathing of the septal occluder so that the proximal disc would deploy in the RA, engaging the right aspect of the IAS. A short wiggle of the delivery system then released the left atrial disc from the LUPV position, engaging the IAS from the left aspect with a perfect configuration for ASD closure (Video 18). TEE investigation showed that the device embraced the aortic root and was in an adequate position in the presence of deficient aortic rim (Video 19). The pulmonary vein slide-out technique has also been used to aid closure of ASDs with deficient posterior rim [20]. This morphology is considered a risk factor for device migration.

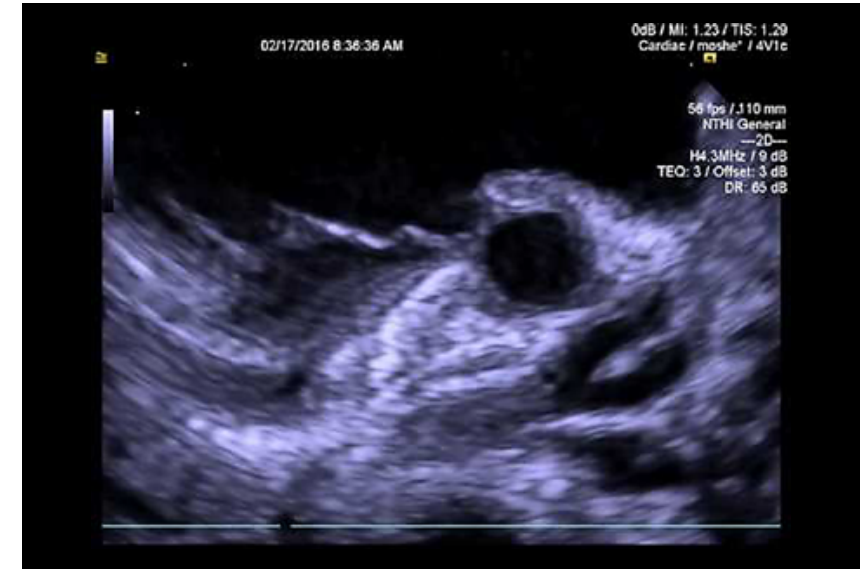

Video 16. Atrial septal defect with deficient aortic rim with an occluder in situ embracing the aortic root. View supplemental video at http://dx.doi.org/10.12945/j.jshd.2016.005.16.vid.16.

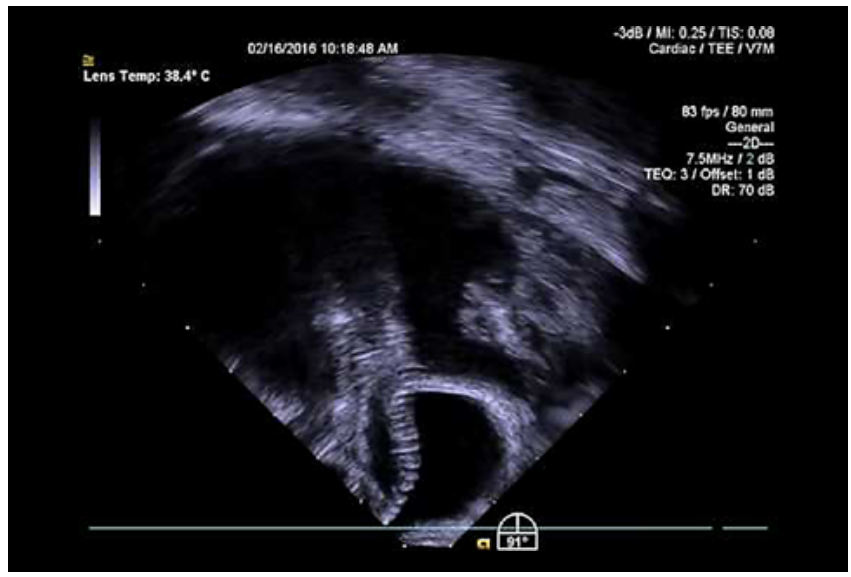

Video 17. The device was malaligned with the septum. View supplemental video at http://dx.doi.org/10.12945/j.jshd.2016.005.16. vid.17.

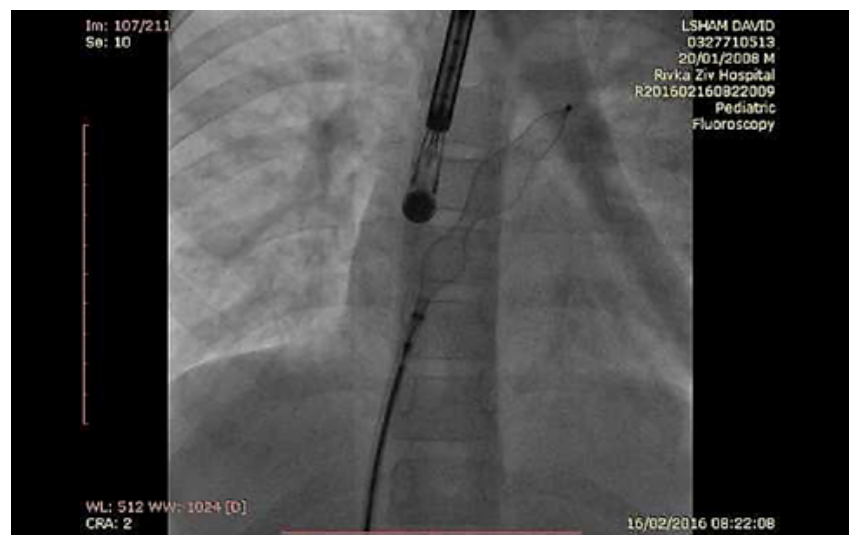

Video 18. The left disc was partially deployed in upper left pulmonary vein, allowing proper right disc deployment. View supplemental video at http://dx.doi.org/10.12945/j.jshd.2016.005.16. vid.18. 


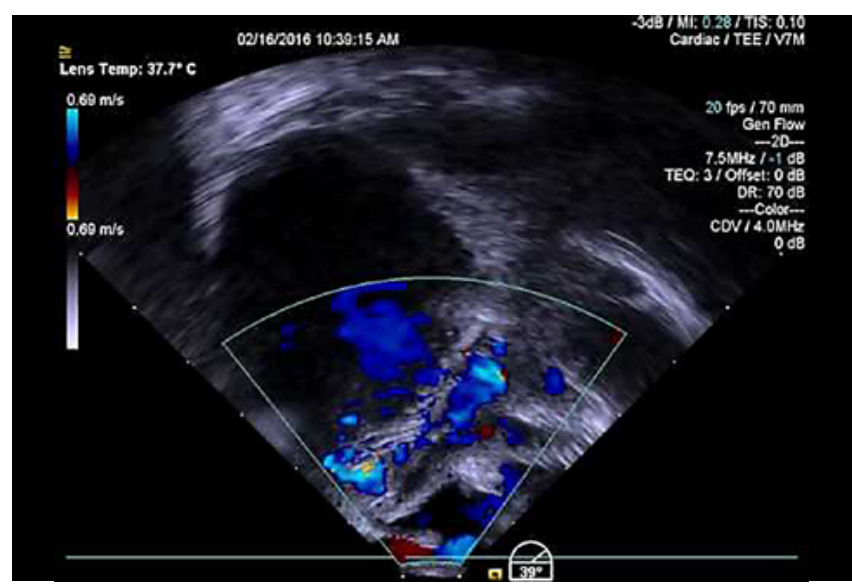

Video 19. The device assumed a normal position. View supplemental video at http://dx.doi.org/10.12945/j.jshd.2016.005.16. vid.19.

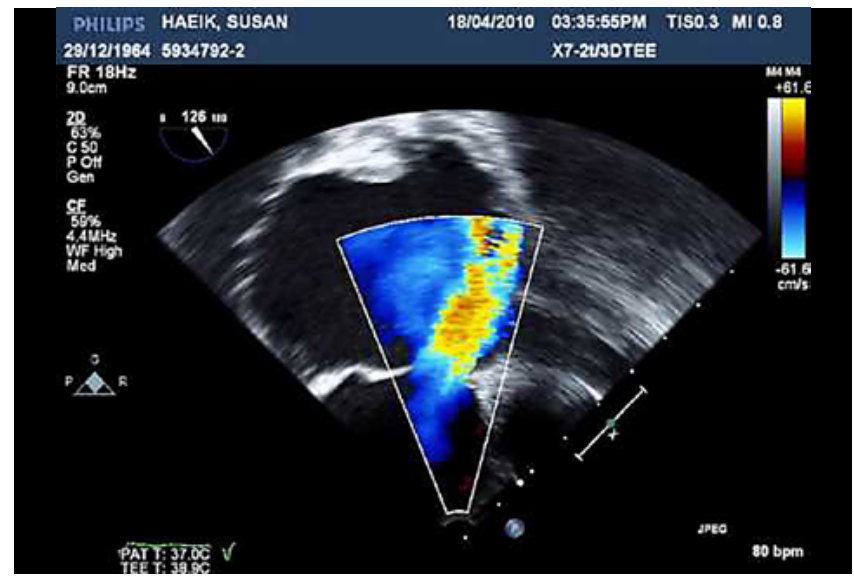

Video 20. Secundum atrial septal defect near the superior vena cava opening into the right atrium. View supplemental video at http://dx.doi.org/10.12945/j.jshd.2016.005.16.vid.20.

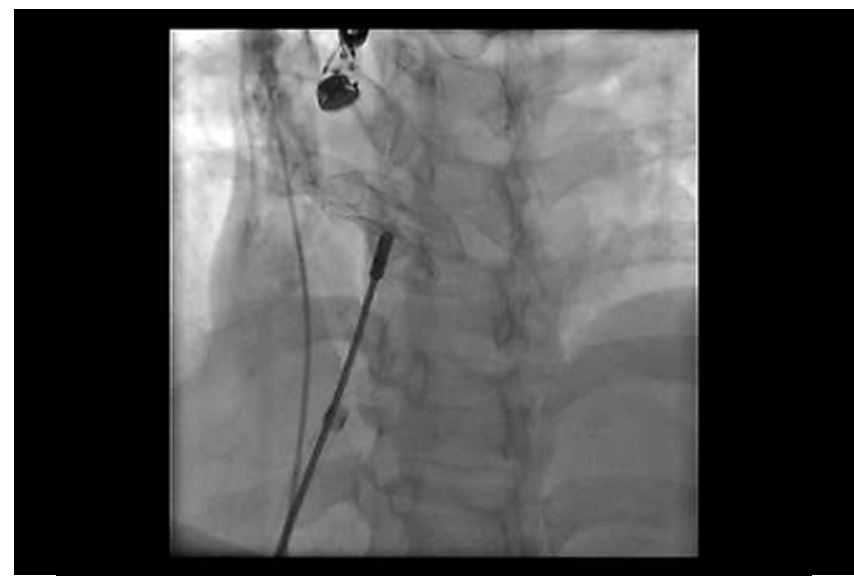

Video 21. Contrast injection in the superior vena cava confirmed no obstruction to superior vena cava flow. View supplemental video at http://dx.doi.org/10.12945/j.jshd.2016.005.16.vid.21.

\section{“High" ASD}

A "high"-positioned ASD, located in the postero-superior IAS, must be differentiated from sinus venosus defect, which may be described as the unroofing of right pulmonary veins into the superior vena cava (SVC) or the RA. Whereas sinus venosus defect cannot be closed by transcatheter intervention in the presence of partially anomalous pulmonary venous drainage, an attempt to close a high ASD can be made. Using TEE, we encountered an ASD in close proximity/ continuity to the entrance of the SVC into the RA (Video 19). Occluding this ASD with a device carries a risk of restricting inflow from the SVC [21] and thrombus formation [22]. Therefore, during the procedure, after the device was deployed in the defect and prior to its release, contrast injection into the SVC in a steep left anterior oblique projection through an additional venous catheter demonstrated the spatial relationship between the SVC-RA junction and the occlusive device (Video 20) and showed unobstructed blood flow from the SVC to the RA (Video 21).

\section{Large Chiari Network}

The Chiari network is a fenestrated membrane consisting of threads and strands in the RA. It is a congenital remnant resulting from incomplete resorption of the right valve of the sinus venosus. Prominent Chiari network may be found in $2-3 \%$ of the population, but it is generally not of clinical importance. During transcatheter occlusion of ASD, the Chiari network can complicate the procedure by catheter entrapment [23], proximal disc entanglement and inadequate deployment [24], and residual shunt [25]. In our situation, the use of an additional catheter in the SVC was also helpful as in our previous case of "high" ASD. A catheter advanced from the femoral vein to the SVC may retain the Chiari network away from the IAS, thus lowering the probability of device or catheter entanglement.

\section{Double Interatrial Septum}

A 37-year-old patient with end-stage renal failure, who was awaiting renal transplantation from his wife, was referred for an elective percutaneous closure of 


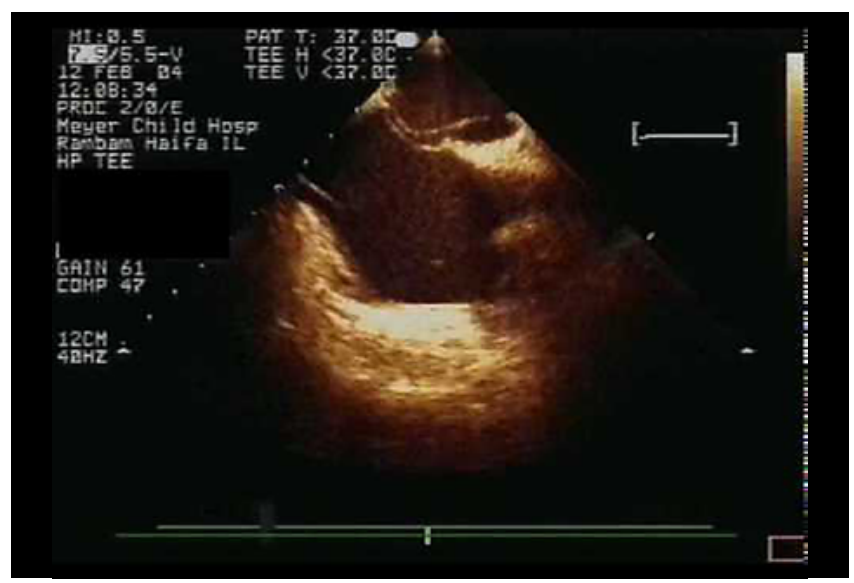

Video 22. Double interatrial septum. View supplemental video at http://dx.doi.org/10.12945/j.jshd.2016.005.16.vid.22.

an ASD. The ASD was diagnosed incidentally on TTE while investigating atypical chest pain. The transplanting team demanded resolution of the cardiac anomaly prior to renal transplantation. Interestingly, there was a familial occurrence of ASD, as his father, three out of 10 siblings, and his son had previously undergone surgical repair of ASD. On TEE, marked RA and ventricular enlargement were noted, and an unusual morphology of the interatrial septum was encountered (Video 22). Two almost parallel ASDs were noted: a $23-\times 28-\mathrm{mm}$ defect in the normally located IAS and a 30-mm defect in the additional curtain located within the LA. The margins of the defects were quite flimsy. We observed normal pulmonary and systemic venous connections. No veins drained into the interatrial space formed between the double atrial septum. The atrial shunt was successfully closed with a single 38-mm Amplatzer ASO on first attempt. The distal disc was deployed in the LA distal to the accessory septum, whereas the proximal disc was deployed in the RA proximal to the normally located septum. Hence, the double atrial septum was fully approximated by the Amplatzer device. No residual shunt was noted during a 10-year follow-up period. The device had aligned well with the combined squashed septum. Percutaneous ASD closure in this patient was especially advantageous, as his end stage renal failure could critically complicate a surgical procedure.

Double atrial septum is an extremely rare atrial

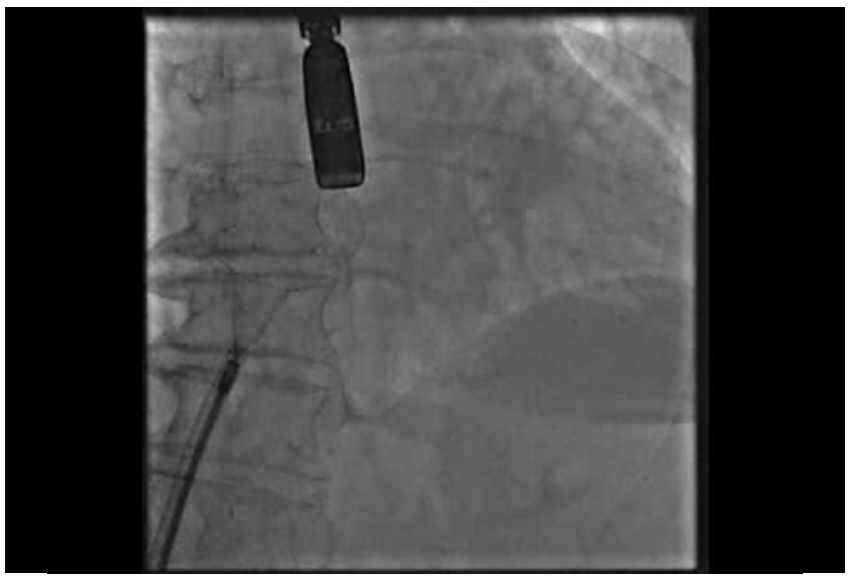

Video 23. Improper deployment of the entire device in the left atrium. View supplemental video at http://dx.doi.org/10.12945/j. jshd.2016.005.16.vid.23.

septal anomaly. It forms an interatrial space that usually communicates with the LA via a patent foramen ovale and with the RA via accessory atrial septal fenestration. These two passages are frequently formed at different levels, such as superior and inferior $[26,27]$. Pulmonary veins may drain in the interatria I space; in this scenario, percutaneous ASD closure may occlude the drainage of this pulmonary vein. Surgical resection of the accessory atrial septum with ASD closure would be the appropriate approach. A pigtail catheter advanced into the right ventricle (RV) may aid in differentiating between double atrial septum and a prominent Eustachian valve; the diagnosis of double septum would be confirmed by a non-deflecting tissue, whereas a Eustachian valve would be drawn away by the catheter [28]. In our patient, we were able to pass the guide wire, the balloon sizing catheter, the delivery sheath, and subsequently the occluding device through both defects and also to achieve an adequate position and configuration of the device with optimal defect occlusion.

\section{Snaring a Runaway Occluder}

A 65-year-old woman with an ASD with deficient antero-superior rim and a floppy IAS underwent percutaneous closure of the ASD. Balloon-sizing of the defect measured $27 \mathrm{~mm}$. A 30-mm OccluTech septal occluder was selected. TEE inaccurately suggested an adequate deployment of the device 


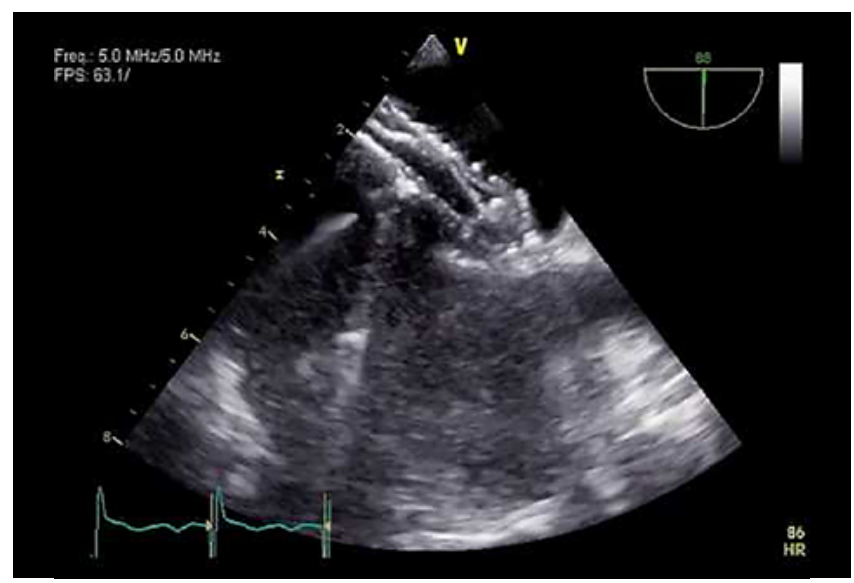

Video 24. "Cobra"-shape disfiguration of the left disc. View supplemental video at http://dx.doi.org/10.12945/j.jshd.2016.005.16. vid.24.

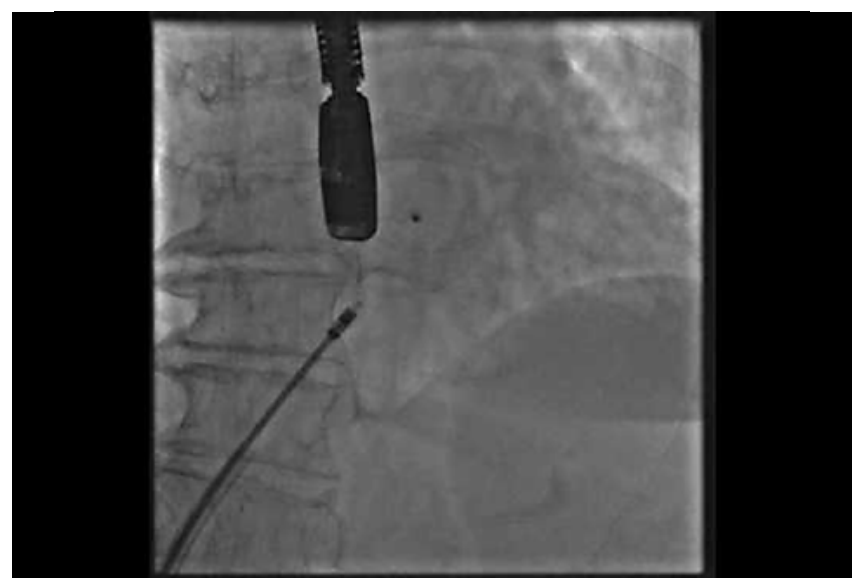

Video 25. A floating device in the left atrium following its release. View supplemental video at http://dx.doi.org/10.12945/j. jshd.2016.005.16.vid.25.

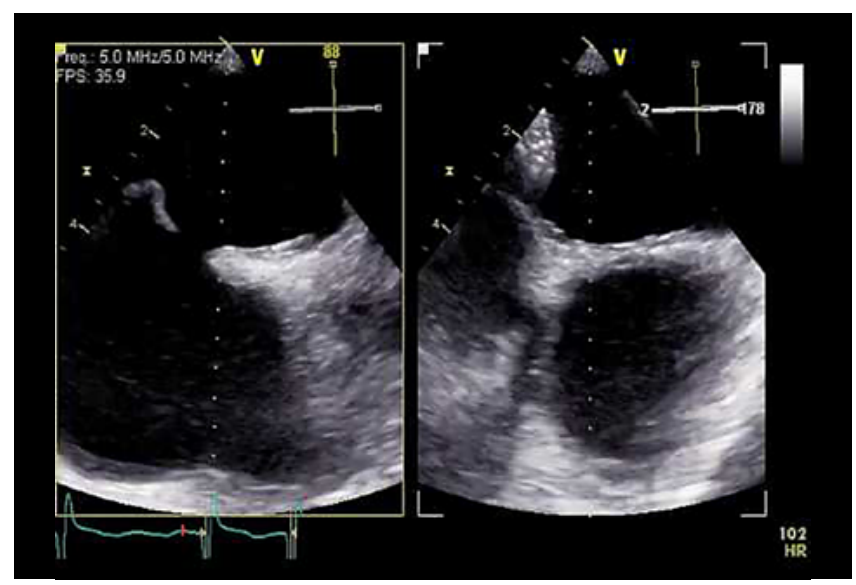

Video 26. A floating device in the left atrium following its release. View supplemental video at http://dx.doi.org/10.12945/j. jshd.2016.005.16.vid.26.

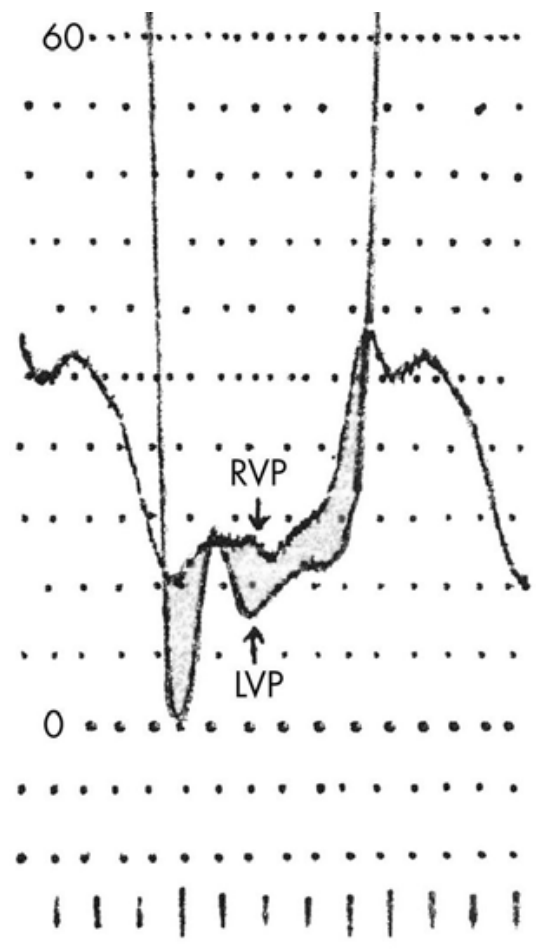

Figure 6. Simultaneous left ventricle (LV) and right ventricle (RV) pressure tracings during catheterization demonstrating higher diastolic pressure in the RV than in the LV.

(Videos 23 and 24). Following release, the device floated in the LA (Videos 25 and 26). The patient was given a supplement of heparin in addition to the initial dose. An attempt to retrieve the device with a $15-\mathrm{mm}$ Andra snare failed. Although it was possible to hold on to the hub of the device, the grip was not strong enough to pull the device back into the $12 \mathrm{~F}$ sheath (Video 27). Finally, the retention hub of the device was grabbed by 7F Cordis biopsy forceps (Video 28), allowing the right disc to be retrieved into the sheath (Video 29). The left disc was then approximated to the IAS, and the device was successfully deployed in the defect (Videos 30 and 31). The entire procedure was prolonged by $25 \mathrm{~min}$. TTE confirmed an adequate position of the occluder the next day. In this scenario, attempting to recapture the connecting hub and accomplishing the procedure is desirable $[29,30]$. Snaring and removing the device is another option. Emergent open-heart surgery is the last resort and should be reserved for unsuccessful device retrieval. 


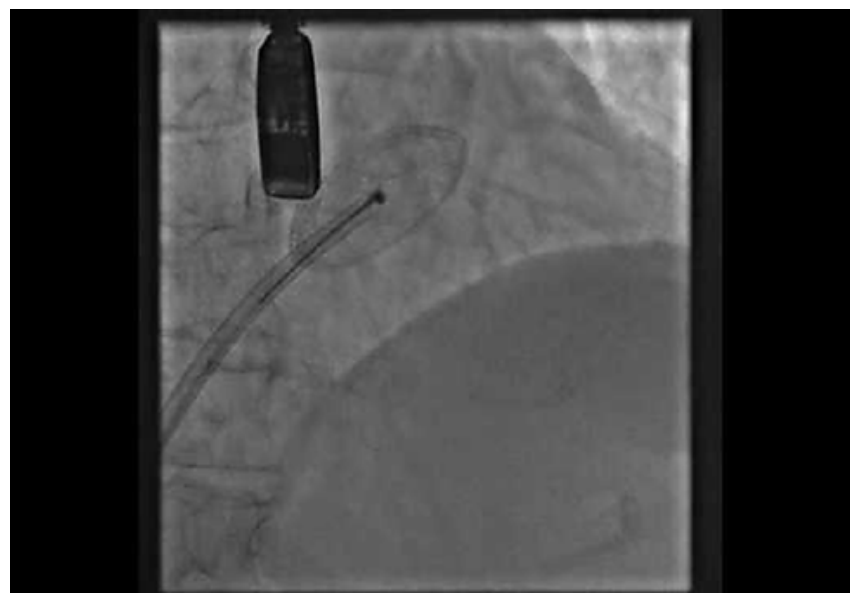

Video 27. Snaring attempts. View supplemental video at http:// dx.doi.org/10.12945/j.jshd.2016.005.16.vid.27.

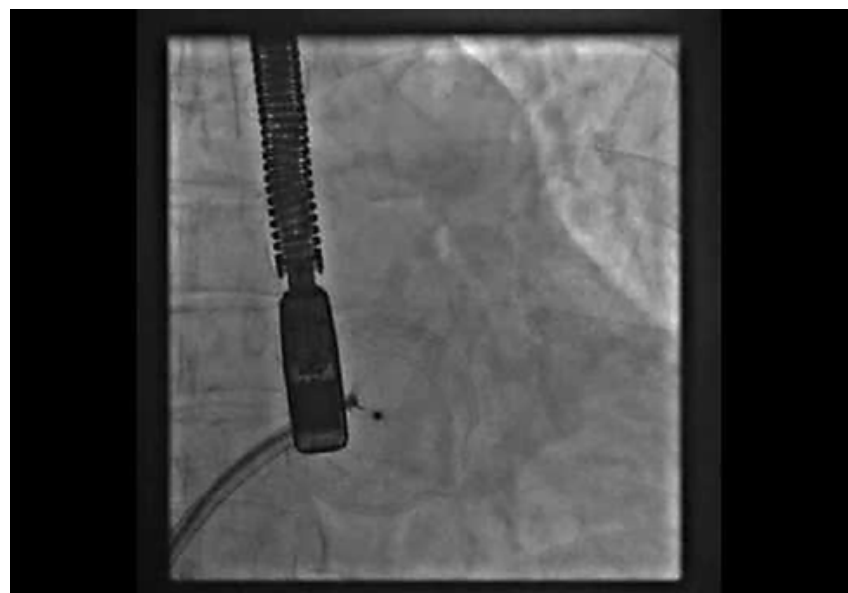

Video 28. The device was seized and retrieved by biopsy forceps. View supplemental video at http://dx.doi.org/10.12945/j. jshd.2016.005.16.vid.28.

\section{RV Diastolic Dysfunction Causing Cyanosis}

A 73-year-old woman presented with profound central cyanosis and a history of minor stroke. She had normal heart morphology, normal pulmonary artery pressure, and normal coronary angiography. A massive right-to-left shunt was demonstrated at atrial level, with normal pulmonary venous saturations and $\mathrm{PO} 2$ values. The reason for this huge right-to-left shunt is illustrated by the diastolic pressure curves, representing compliance differences between the right and left ventricles (Figure 6). Other causes of atrial right-to-left shunt, including pulmonary disease, pulmonary vascular disease, RV hypertrophy, RV

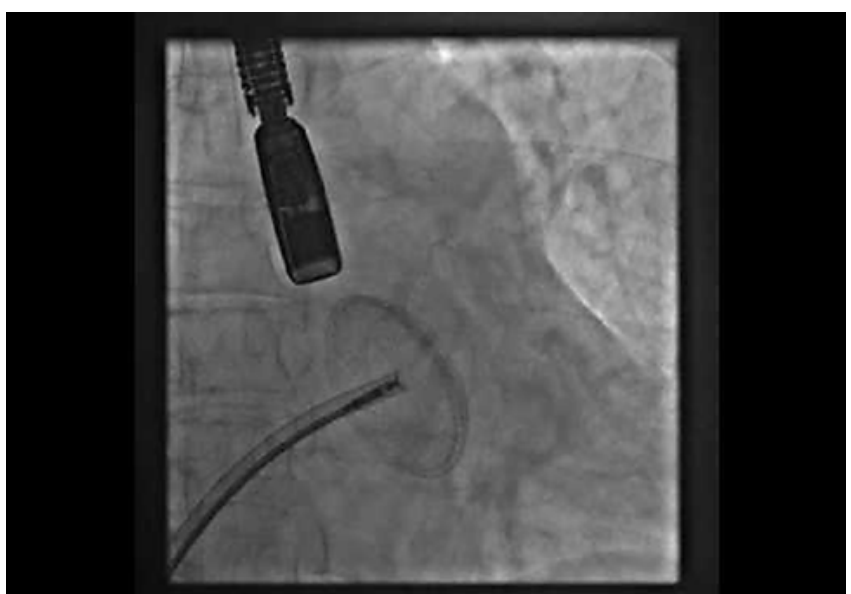

Video 29. The device was seized and retrieved by biopsy forceps. View supplemental video at http://dx.doi.org/10.12945/j. jshd.2016.005.16.vid.29.

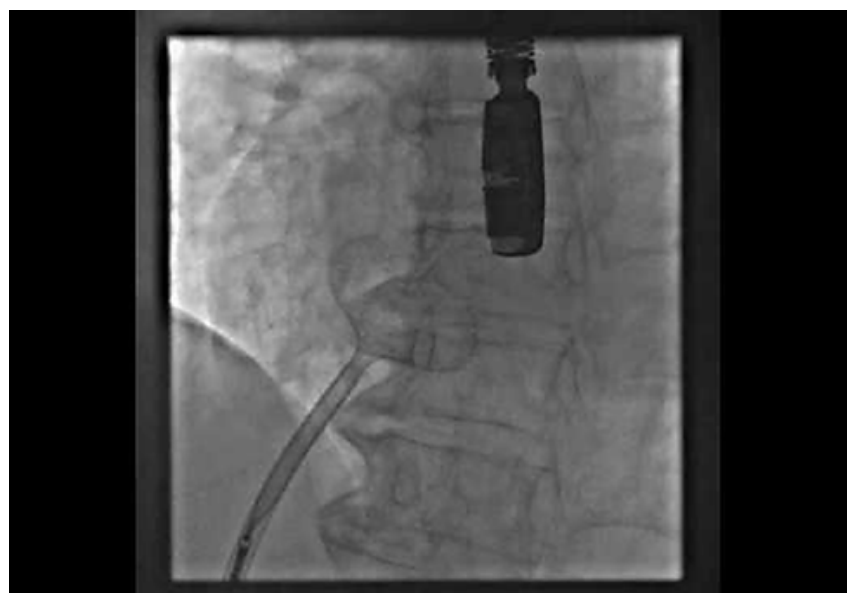

Video 30. Re-deployment of the device. View supplemental video at http://dx.doi.org/10.12945/j.jshd.2016.005.16.vid.30.

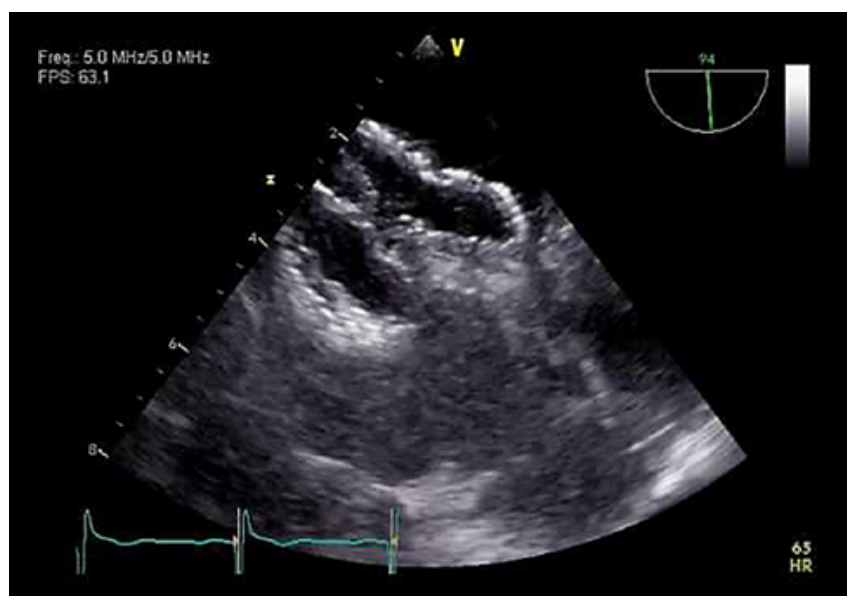

Video 31. Re-deployment of the device. View supplemental video at http://dx.doi.org/10.12945/j.jshd.2016.005.16.vid.31. 
systolic dysfunction, RA myxoma, tricuspid valve disease, and pericardial effusion, were excluded. Balloon occlusion of the patent foramen ovale served to test the tolerance of the occlusion and measure the effective stretched defect size. The defect was then closed by a 24-mm ASD Amplatzer occluder, resulting in a rise of arterial PO2 from 40 to $320 \mathrm{mmHg}$.

Atrial-level right-to-left shunt (ARLS) is a rare but important cause of hypoxia. The pathophysiology arises from an interatrial defect coupled with a secondary cardiac or pulmonary insult. A rise in RA pressure above LA pressure may precipitate ARLS [31]. Diastolic RV dysfunction may be caused by different mechanisms, including acute myocardial infarction, age-related undiagnosed severe pulmonary stenosis, and pulmonary atresia with intact interventricular septum years following resolution of RV outflow obstruction [32]. Treatment of ARLS involves treating the underlying cause and/or closure of the shunt to resolve hypoxemia. Observing the tolerance of a temporary closure of the ASD with a sizing balloon while monitoring RA pressure and systemic blood pressure should prevent RA pressure elevation and reduce cardiac output. If balloon occlusion is well-tolerated, the ASD (or patent foramen ovale) may be closed safely with a device and result in a favorable outcome.

Pulmonary arterial hypertension may also lead to ARLS in the presence of interatrial communication. However, prior to attempting to close an ASD in this situation, the reversibility of pulmonary hypertension should be demonstrated to avoid RV failure. A bal- loon occlusion test with RA pressure monitoring is a prudent approach. A fenestrated occluder may be considered as a temporary vent mechanism [33].

\section{Summary}

We present these select cases as challenges that require pre-procedural planning and intra-procedural considerations to successfully perform the percutaneous approach as an alternative to surgery without compromising patient safety. Some complex ASDs may be better treated by the surgeon, avoiding unpredictable percutaneous interventional outcome. Mature judgement and the acknowledgement of the current technology limitations is needed to hand over cases to the surgical team. However, the interventional team is expected to be resourceful in preparing for and performing the procedure. Learning from others' experience, as well as the prudent use of imaging modalities, personal experience, and proper selection of equipment, are beneficial when managing complex cases of ASD closure.

\section{Conflict of Interest}

The authors have no conflict of interest relevant to this publication.

\section{Comment on this Article or Ask a Question}

\section{References}

1. Du ZD, Hijazi ZM, Kleinman CS, Silverman $\mathrm{NH}$, Amplatzer investigators. Comparison between transcatheter and surgical closure of secundum atrial septal defect in children and adults: results of a multicenter nonrandomized trial. J Am Coll Cardiol. 2002;39:1836-1844. DOI: 10.1016/S07351097(02)01862-4

2. Tal R, Dahud Q, Lorber A. Fenestrated atrial septal defect percutaneously occluded by a single device: procedural and financial considerations. Cardiol Ther. 2013;2:97102. DOI: $10.1007 / \mathrm{s} 40119-012-0009-5$

3. Awad SM, Garay FF, Cao QL, Hijazi ZM. Multiple Amplatzer septal occluder devices for multiple atrial communications: immediate and long-term follow-up results. Catheter Cardiovasc Interv. 2007;70:265-273.
DOI: $10.1002 / \mathrm{ccd} .21145$

4. Tillman T, Mulingtapang R, Sullebarger JT. Approach to percutaneous closure in patients with multiple atrial septal defects. J Invasive Cardiol. 2008;20:E167-E170. PMID: 18460721

5. Butera G, Romagnoli E, Saliba Z, et al. Percutaneous closure of multiple defects of the atrial septum: procedural results and long-term follow-up. Catheter Cardiovasc Interv. 2010;76:121-128. DOI: 10.1002/ ccd. 22435

6. Szkutnik M, Masura J, Bialikowski J, Gavora P, Banaszak P, Kusa J, et al. Transcatheter closure of double atrial septal defects with a single Amplatzer device. Catheter Cardiovasc Interv. 2004;61:237-241. DOI: 10.1002/ccd.10753

7. El Saiedi SA, Attia WA. New pediatric version of balloon-assisted technique for atrial septal defect closure using self-centering devices: Relation to interatrial septal thickness. J Invasive Cardiol. 2015;27:510515. PMID: 26524205

8. Narin N, Baykan A, Argun M, Ozyurt A, Pamukcu O, Bayram A, et al. New modified balloon-assisted technique to provide appropriate deployment in the closure of large secundum atrial septal defect using amplatzer septal occluder in children. J Invasive Cardiol. 2014;26:597-602. PMID: 25364001

9. Pillai AA, Rangaswamy Balasubramanian V, Selvaraj R, Saktheeswaran M, Satheesh 
S, Jayaraman B. Utility of balloon assisted technique in trans catheter closure of very large $(\geq 35 \mathrm{~mm})$ atrial septal defects. Cardiovasc Diagn Ther. 2014;4:21-27. DOI: 10.3978/j.issn.2223-3652.2014.02.05

10. Fu YC, Cao QL, Hijazi ZM. Device closure of large atrial septal defects: technical considerations. J Cardiovasc Med (Hagerstown). 2007;8:30-33. DOI: 10.2459/01. JCM.0000247432.74699.47

11. Wahab HA, Bairam AR, Cao QL, Hijazi ZM. Novel technique to prevent prolapse of the Amplatzer septal occluder through large atrial septal defect. Catheter Cardiovasc Interv. 2003;60:543-545. DOI: 10.1002/ ccd. 10686

12. Fischer G, Stieh J, Uebing A, et al. Experience with transcatheter closure of secundum atrial septal defects using the Amplatzer septal occlude: A single centre study in 236 consecutive patients. Heart. 2003;89:199-204. PMID: 12527678

13. Mazic U, Gavora P, Masura J. “Cobra-like” deformation of an Amplatzer septal occluder. Pediatr Cardiol. 2001;22:253-254. DOI: 10.1007/s002460010216

14. Estévez-Loureiro R, Martínez-Bendayan I, Salgado-Fernández J, Rueda-Núñez F. Cobra-like deformation of Amplatzer devices used for closing atrial septal defects: Can it be avoided? Rev Esp Cardiol. 2010;63:495496. DOI: $10.1016 / \mathrm{S} 1885-5857(10) 70103-1$

15. Aaron S, Mainzer G, Lorber A. Taming the "cobra": an approach to "cobra-like" formation seen in the Occlutech atrial septal defect and patent foramen ovale occluders. Catheter Cardiovasc Interv. 2012;79:678680. DOI: $10.1002 / \mathrm{ccd} .23303$

16. Pillai AA, Satheesh S, Pakkirisamy G, Selvaraj $R$, Jayaraman $B$. Techniques and outcomes of transcatheter closure of complex atrial septal defects - single center experience. Indian Heart J. 2014;66:38-44. DOI: 10.1016/j.ihj.2013.12.016

17. Ostermayer SH, Srivastava S, Doucette JT, Ko HH, Geiger M, Parness IA, et al. Malattached septum primum and deficient septal rim predict unsuccessful transcatheter closure of atrial communications. Catheter Cardiovasc Interv. 2015;86:1195-1203. DOI: 10.1002/ccd.26102.

18. O'Byrne ML, Glatz AC, Sunderji S, Mathew $A E$, Goldberg DJ, Dori Y, et al. Prevalence of deficient retro-aortic rim and its effects on outcomes in device closure of atrial septal defects. Pediatr Cardiol. 2014;35:11811190. DOI: 10.1007/s00246-014-0914-6.

19. Romanelli G, Harper RW, Mottram PM. Transcatheter closure of secundum atrial septal defects: results in patients with large and extreme defects. Heart Lung Circ. 2014;23:127-131. DOI: 10.1016/j. hlc.2013.07.020.

20. Papa M, Gaspardone A, Fragasso G, Sidoti $F$, Agricola $E$, Geoffrè $G$, et al. Feasibility and safety of transcatheter closure of atrial septal defects with deficient posterior rim. Catheter Cardiovasc Interv. 2013;81:11801187. DOI: $10.1002 / c c d .24633$.

21. Kahya Eren N, Kocabaş U, Nazlı C, Ergene $O$. Obstruction of superior vena cava flow during transcatheter atrial septal defect closure with the Atriasept ASD occluder. Turk Kardiyol Dern Ars. 2013;41:141-143. DOI: 10.5543/tkda.2013.95580.

22. Bijulal S, Sivasankaran S, Ajitkumar VK. An unusual thrombotic complication during percutaneous closure of atrial septal defect. J Invasive Cardiol. 2009;21:83-85.

23. Aydın A, Gürol T, Yılmazer MS, Dağdeviren B. Catheter entrapment around the Chiari network during percutaneous atrial septal defect closure. Anadolu Kardiyol Derg. 2011;11:E6-E7. DOI: 10.5152/akd.2011.047.

24. Cooke JC, Gelman JS, Harper RW. Chiari network entanglement and herniation into the left atrium by an atrial septal defect occluder device. J Am Soc Echocardiogr. 1999;12:601-603.

25. Greutmann $M$, Greutmann-Yantiri $M$, Kretschmar O, Senn O, Roffi M, Jenni R, et al. Percutaneous PFO closure with Amplatzer PFO occluder: predictors of residual shunts at 6 months follow-up. Congenit Heart Dis. 2009;4:252-257. DOI: 10.1111/j.17470803.2009.00302.x.

26. Kim IS, Jin MN, Song C, Kim YJ, Ji AY, Son $\mathrm{JW}$, et al. The case of isolated double atrial septum with persistent interatrial space. J
Cardiovasc Ultrasound. 2013;21:197-199. DOI: 10.4250/jcu.2013.21.4.197.

27. Roberson DA, Javois AJ, Cui W, Madronero $L F$, Cuneo BF, Muangmingsuk S. Double atrial septum with persistent interatrial space: echocardiographic features of a rare atrial septal malformation. J Am Soc Echocardiogr. 2006;19:1175-1181. DOI: 10.1016/j.echo.2006.04.001.

28. Freixa X, Regueiro A, Neves de Araujo G, Leal N, Sabaté M. Double atrial septum or redundant Eustachian valve: procedural management during atrial septal defect occlusion. Eurolntervention. 2015;11:e1e2. DOI: 10.4244/EIJV1116A141.

29. Peuster M, Boekenkamp R, Kaulitz R, Fink C, Hausdorf G. Transcatheter retrieval and repositioning of an Amplatzer device embolized into the left atrium. Catheter Cardiovasc Interv. 2000;51:297-300.

30. Ahn J, Kim JH, Choi JH, Oh JH. Percutaneous retrieval and redeployment of an atrial septal occluder under three-dimensional transesophageal echocardiographic guidance: a case report. J Korean Med Sci. 2014;29:871-873. DOI: 10.3346/ jkms.2014.29.6.871.

31. Shnaider $H$, Shiran A, Lorber A. Right ventricular diastolic dysfunction and patent foramen ovale causing profound cyanosis. Heart. 2004;90:e31.

32. Gelernter-Yaniv L, Khoury A, Schwartz Y, Lorber A. Transcatheter closure of rightto-left interatrial shunts to resolve hypoxemia. Congenit Heart Dis. 2008;3:47-53. DOI: 10.1111/j.1747-0803.2007.00157.x.

33. Tal R, Schwartz $Y$, Lorber A. Staged approach for the management of ASD in presence of a small left ventricle and supra-systemic pulmonary pressure. Curr Res Cardiol. 2014;2:114-116.

Cite this article as: Tal $R$, Dotan $M$, SchwartzY, Lorber A. Challenges in Atrial Septal Defect Occlusion. Structural Heart Disease. 2017;3(1):15-27. DOI: http://dx.doi.org/10.12945/j. jshd.2017.16.005 